\title{
Determinants of life satisfaction and self-rated health in Iranian children and adolescents: A structure equation model
}

\author{
Pooneh Angoorani \\ Tehran University of Medical Sciences \\ Zohreh Mahmoodi \\ Alborz University of Medical Sciences \\ Hanieh-Sadat Ejtahed \\ Tehran University of Medical Sciences \\ Ramin Heshmat \\ Tehran University of Medical Sciences \\ Mohammad Esmaeil Motlagh \\ Ahvaz Jundishapur University of Medical Sciences \\ Mostafa Qorbani ( $\triangle$ mqorbani1379@yahoo.com) \\ Alborz University of Medical Sciences \\ Roya Kelishadi \\ Isfahan University of Medical Sciences
}

\begin{abstract}
Research Article
Keywords: Life satisfaction, self-rated health, CASPIAN, children
\end{abstract}

Posted Date: June 30th, 2021

DOI: https://doi.org/10.21203/rs.3.rs-17825/v3

License: (c) (i) This work is licensed under a Creative Commons Attribution 4.0 International License. Read Full License

Version of Record: A version of this preprint was published at BMC Pediatrics on January 3rd, 2022. See the published version at https://doi.org/10.1186/s12887-021-03044-w. 


\section{Abstract \\ Background}

Life satisfaction (LS) and self-rated health (SRH) are related with health outcomes. It is expected that these items are also related to healthy behaviors. Therefore, this study was conducted in order to find out the main determinants of LS and SRH in nationwide representative sample of Iranian children and adolescents.

\section{Methods}

This study was performed on 13834 students aged 7-18 years who were selected by multistage, stratified cluster sampling method from 30 provinces of Iran. LS and SRH were assessed through a questionnaire based on World Health Organization-Global School-based Student Health Survey protocols. Path analysis was applied to evaluate the relationships among the study variables using the structural modeling.

\section{Results}

LS was directly affected by age ( -0.037 in boys \& -0.028 in girls); sedentary time ( 0.055 in boys \& 0.048 in girls); school satisfaction ( 0.249 in boys \& 0.250 in girls); and well-being ( 0.186 in boys \& 0.176 in girls). SRH was directly affected by LS ( 0.28 in boys \& girls) and school satisfaction ( 0.21 in boys \& 0.22 in girls); and indirectly affected by age (-0.046 in boys \& -0.017 in girls); sedentary time ( -1.99 in boys \& -0.145 in girls); family size $(-0.005$ in boys $\&-0.014$ in girls); and socio-economic status ( 0.015 in boys $\& 0.058$ in girls).

\section{Conclusions}

This study indicated that school satisfaction had the greatest positive direct effect on both LS and SRH.

\section{Introduction}

Childhood and adolescence are considered to be a life phase in which future health patterns for adulthood are being initiated. It is characterized as a period of relatively good physical and mental health, high life satisfaction, and low mortality. During this developmental outlook, low life satisfaction and bad health condition can have a diverse effect on the improvement of developmental challenges related to adolescence and ultimately lead to several long-term negative consequences in adulthood $(1,2)$. Although infectious disease, malnutrition, and mortality have been lowered in children and adolescent populations, however, shifting attention to chronic diseases, mental health problems, obesity, and physical illness, which their prominence during childhood and adolescence is very concerning (3). Life satisfaction (LS) and self-rated health (SRH), assess different dimensions of individuals' own health that show some non-biomedical factors of general well-being framed by individual, familial and social dimensions (4). LS can be defined as the degree to which an individual judges the overall quality of his life-as-a-whole favorably (5). SRH is considered a powerful global indicator of health and mortality that show the effects of some non-biomedical factors, such as lifestyle, psychosocial, and sociodemographic conditions (6). An increasing body of literature has been conducted regarding the relationship between LS and factors related to social conditions such as the individual's living conditions or society-level, economic well-being, and physical and mental health on adult populations (79). However, there is limited practical investigation on SRH and LS for children or adolescents. We conducted this study in order to comprehend main determinants of LS and SRH in a nationwide representative sample of Iranian children and adolescents according to the path analysis, as a powerful statistical model in evaluating a complex cluster of dependent variables (10).

\section{Methods}

This nationwide study was conducted in urban and rural areas of Iran in 2015 as the fifth national survey of a school-based surveillance program entitled the Childhood and Adolescence Surveillance and Prevention of Adult Non-communicable disease (CASPIAN-V) study. Data was checked at the district level by academic supervisors (expert of school health) and controlled by national supervisors and operators. Detailed description of the sampling and data collection methods are published previously (11). Briefly, here we explain the methodology of the CASPIAN-V study.

\section{Study population and sampling framework}

The study population consisted of students aged 7-18 years in primary and secondary schools in urban and rural areas across the country. Students were selected by multistage, stratified cluster sampling method from 30 provinces of the country (48 clusters of 10 students in each province). Stratification was performed in each province according to the residence area (urban/rural) and level of education (primary/ secondary). The sampling size was proportional to population in each urban or rural area with equal sex ratio. Cluster sampling with equal clusters was used in each province to reach the necessary sample size. Clusters were determined at the level of schools, including 10 statistical units (students and their parents) in each cluster. 


\section{Questionnaires}

Two sets of the questionnaires were used for students and their parents. The questionnaires were obtained from Global School Student Health Survey (GSHS) that translated to Persian (12). The reliability and validity of the Persian version of questionnaires was approved in the previous studies $(13,14)$.

The student questionnaire included questions regarding body image, psychosocial environment of school, dietary habits, life-style habits, and violence behavior. Trained personnel completed questionnaires in a calm atmosphere inside the schools; the whole process was supervised and controlled by a team of health care professionals.

Issues such as family composition, economic and socio-demographic factors, genetic determinants (family history of hypertension, diabetes, and obesity), past history of student (birth weight, breastfeeding, and type of complementary food), and family dietary habits were included in the parent's questionnaire which was completed by the parents themselves.

\section{Measuring tools}

The questionnaire of the World Health Organization-Global School-based Student Health Survey (WHO-GSHS) was used to assess aggressive behaviors, LS, SRH and counseling with family members. Demographic information on age, gender, residence area, family based characteristics, living with parents, parental level of education, possessing a family private car and type of home gathered through interview with students.

Life satisfaction (LS) was assessed through a single item. Students were asked to indicate their degree of life satisfaction by using a tenth-point scale from $1=$ very dissatisfied to $10=$ very satisfied. Fewer than 6 responses were aligned to dissatisfaction and responses of equal and upper 6 were defined as satisfaction.

Self-rated health (SRH) was assessed through a single item, "how would you describe your general state of health?"; the categories of response were "perfect", "good", "bad," and "very bad". For statistical analysis, "perfect and good" responses were considered as "good SRH". Moreover, the preference of participant in consulting with father, mother, and sister/brother and friends were asked for further analyses.

Physical activity was assessed through a validated questionnaire including weekly frequency of leisure time physical activity outside the school during the past week, and having sufficient physical activity was defined as at least 30 min of exercise per day that led to sweating and large increases in breathing or heart rate $(12,15)$.

Sedentary time was considered as the average number of hours per day spent watching television or using computer assessed with a validated questionnaire $(12,15)$.

Socioeconomic status (SES) was calculated through a questionnaire included questions about the following socioeconomic indicators: (a) parental level of education (illiterate: score 1, less than high school: score 2, high school graduate: score 3, academic education: score 4); (b) parental occupational status (unemployed: score 1, worker/farmer: score 2, governmental employee: score 3, self-employed: score 4); (c) number of inhabitants in home, and (d) possessing a family private car (yes/no). It should be noted that for questions (a) and (b) (i.e. parental occupational status and level of education) data from the parent with a higher occupational status/education was considered.

School satisfaction was assessed through a validated questionnaire regarding the overall satisfaction with school life experience including interest in learning tasks, attitude to homework, school environment, relationships with teachers and classmates.

Social contact was assessed through a validated questionnaire regarding social relationship, the number of friends and time spend with them.

Well-being was considered as the overall satisfaction with relationships with family members and friends and current life conditions.

\section{Anthropometric measurements}

Trained healthcare staff conducted the anthropometric measurement according to the standard protocol. Height was measured without shoes to the nearest $0.5 \mathrm{~cm}$. Weight was measured with light clothes to the nearest $0.1 \mathrm{~kg}$. Body mass index (BMI) was calculated as weight (kg) divided by square of height $\left(\mathrm{m}^{2}\right)$. Waist circumference (WC) was measured at the point midway between the lower border of the rib cage and the iliac crest to the nearest $0.1 \mathrm{~cm}(11)$. Waist to height ration was calculated by dividing WC to height.

\section{Ethical concerns}

The protocols of the present study were assessed and approved by the Research and Ethics Council of Isfahan University of Medical Sciences (Project Number: 194049). Written informed consent and verbal consent was obtained from the parents and students, respectively (11). This study 
was conducted according to the guidelines laid down in the Declaration of Helsinki, and all procedures involving human subjects were approved by Ethics Committee of Isfahan University of Medical Sciences.

\section{Statistical analysis}

All variables were checked for normality and expressed as means (standard deviation, SD). Student's two-tailed $t$ test was used to compare the mean differences of characteristics between boys and girls. Pearson correlation was applied to examine the relationships between the study variables and to implement the subsequent structural modeling. Path analysis was applied to examine the causal framework. Path analysis includes causal modeling, analysis of covariance structures, and latent variable models. We conceptualized this model according to literature review and our previous studies using causal association in the form of a directed acyclic graph between the explanatory variables with outcomes (LS-SRH). This model is a generalization of multivariate multiple regression that allows one to estimate the strength and sign of direction and indirection association for complicated causal schemes with multiple dependent and independent variables $(16,17)$. Path standardized coefficients $(\beta)$ as the effect sizes of associations were calculated. Goodness of fit (GOF) indices (e.g. The Root Mean Square Error of Approximation (RMSEA), the goodness of fit index (GFI), the adjusted GFI) were applied for assessing of fitness of the model (18). All of the statistical analysis was performed using IBM, AMOS and STATA 11.0 (STATA Corp, College Station, TX). P-value less than 0.05 was considered as statistically significant.

\section{Results}

Totally, 13834 students ( $50.7 \%$ boys; mean age: $12.2 \pm 3.15$ years) were assessed in this study. There were no significant differences in age, SES, anthropometric indices, ST, school satisfaction, sleep duration, wellbeing, SRH and LS between boys and girls. However, physical activity and social contact were significantly higher in boys than in girls $(\mathrm{P}<0.001)$. Table 1 shows the correlation among variables according to sex. In both sexes, SRH was positively correlated with age ( $r=0.029$ for boys and $r=0.63$ for girls), school satisfaction $(r=0.312$ for boys and $r=0.326$ for girls), and social contact ( $r=0.034$ for boys and $r=0.044$ for girls), but negatively correlated with LS ( $r=-0.367$ for boys and $r=-0.370$ for girls), physical activity ( $r=-0.057$ for boys and $r=-0.070$ for girls), sedentary time $(r=-0.034$ for boys and $r=-0.035$ for girls), and sleep duration ( $r=-0.097$ for boys and $r=-0.123$ for girls). In both sexes, LS was positively correlated with SES, sleep duration, social contact, and wellbeing, but negatively correlated with age, ZBMI and school satisfaction (the amounts of " $r$ " are illustrated in the Table 2). In both genders the most correlation was observed between SRH and LS ( $r=-0.367$ for boys and $r=-0.370$ for girls). The direct effect of all variables according to sex is presented in Table 2 . In both genders, age showed a positive direct effect on school satisfaction and ZBMl; physical activity had positive direct effect on well-being, social contact and $\mathrm{SRH}$; sedentary time showed positive direct effect on LS and social contact but negative direct effect on physical activity and school satisfaction. The direct, indirect and total effect of variables on LS and SRH is respectively illustrated in Table 3 and 4 . LS was directly affected by age (-0.037 in boys \& -0.028 in girls), sedentary time ( 0.055 in boys \& 0.048 in girls), school satisfaction ( 0.249 in boys \& 0.250 in girls), and well-being ( 0.186 in boys \& 0.176 in girls). The other variables including sleep duration, physical activity, family size, SES, and social contact had slight indirect effect on LS. Among studied variables, only age and sedentary time had both direct and indirect effect on LS. In both genders, school satisfaction had the greatest direct effect and social contact had the greatest indirect effect on LS. 
Table 1

Matrix for Pearson correlation among characteristics

\begin{tabular}{|c|c|c|c|c|c|c|c|c|c|c|c|c|c|}
\hline & & SRH & LS & AGE & W/H & SES & PA & ST & $\begin{array}{l}\text { SLEEP } \\
\text { DU }\end{array}$ & ZBMI & $\begin{array}{l}\text { SOCIAL } \\
\text { CO }\end{array}$ & $\begin{array}{l}\text { Well } \\
\text { being }\end{array}$ & $\begin{array}{l}\text { SCHOOL } \\
\text { S }\end{array}$ \\
\hline \multirow[t]{2}{*}{ SRH } & $\begin{array}{l}\text { Boy } \\
(N= \\
7009)\end{array}$ & 1 & $-.367^{\star \star}$ & $.029^{\star}$ & -.001 & .003 & $-.057^{\star \star}$ & $-.034^{\star \star}$ & $-.097^{\star \star}$ & .019 & $.034^{\star *}$ & $-.19^{\star \star}$ & $.312^{\star \star}$ \\
\hline & $\begin{array}{l}\text { Girl } \\
(N= \\
6825)\end{array}$ & 1 & $-.37^{\star \star}$ & $.63^{\star \star}$ & -.001 & .001 & $-.07^{\star \star}$ & $-.035^{\star \star}$ & $-.123^{\star \star}$ & $0.034^{\star \star}$ & $.044^{\star \star}$ & $.183^{\star \star}$ & $.326^{\star \star}$ \\
\hline \multirow[t]{2}{*}{ LS } & $\begin{array}{l}\text { Boy } \\
(\mathrm{N}= \\
7009)\end{array}$ & & 1 & $-.63^{\star \star}$ & .009 & $.032^{\star \star}$ & $.045^{\star \star}$ & $.067^{\star \star}$ & $.072^{\star \star}$ & -.022 & $.025^{*}$ & $.252^{\star \star}$ & $-.307^{\star \star}$ \\
\hline & $\begin{array}{l}\text { Girl } \\
(\mathrm{N}= \\
6825)\end{array}$ & & 1 & $-.058^{\star \star}$ & $.036^{\star \star}$ & $.034^{\star \star}$ & $.043^{\star \star}$ & $.067^{\star \star}$ & $.067^{\star \star}$ & -.006 & $0.27^{*}$ & $.265^{\star \star}$ & $-.309^{\star \star}$ \\
\hline \multirow[t]{2}{*}{ Age } & $\begin{array}{l}\text { Boy ( } \\
\mathrm{N}= \\
7009)\end{array}$ & & & 1 & -.022 & -.011 & $-.045^{\star \star}$ & $0.49^{\star \star}$ & $-.064^{\star \star}$ & $0.37^{\star \star}$ & 0.003 & $-.38^{\star \star}$ & $.061^{\star \star}$ \\
\hline & $\begin{array}{l}\text { Girl } \\
(\mathrm{N}= \\
6825)\end{array}$ & & & 1 & -.017 & $-.032^{\star \star}$ & $-.027^{\star}$ & $.048^{\star \star}$ & $-.071^{\star \star}$ & $.49^{\star \star}$ & -.009 & $-.05^{\star \star}$ & $.11^{\star \star}$ \\
\hline \multirow[t]{2}{*}{$\mathrm{W} / \mathrm{Ht}$} & $\begin{array}{l}\text { Boy } \\
(\mathrm{N}= \\
7009)\end{array}$ & & & & 1 & $.051^{\star \star}$ & -.02 & $.25^{*}$ & -.005 & $.463^{\star \star}$ & -.008 & .009 & -.018 \\
\hline & $\begin{array}{l}\text { Girl } \\
(\mathrm{N}= \\
6825)\end{array}$ & & & & 1 & $.35^{\star \star}$ & -.012 & -.002 & -.006 & $.484^{\star \star}$ & -.007 & -.01 & -.007 \\
\hline \multirow[t]{2}{*}{ SES } & $\begin{array}{l}\text { Boy } \\
(\mathrm{N}= \\
7009)\end{array}$ & & & & & 1 & $-.04^{\star \star}$ & $-.045^{\star \star}$ & -.019 & $.039^{\star \star}$ & $-.042^{\star \star}$ & .013 & .012 \\
\hline & $\begin{array}{l}\text { Girl } \\
(\mathrm{N}= \\
6825)\end{array}$ & & & & & 1 & $-.027^{\star}$ & .023 & -.015 & .018 & -.015 & .019 & -.001 \\
\hline \multirow[t]{2}{*}{ PA } & $\begin{array}{l}\text { Boy } \\
(\mathrm{N}= \\
7009)\end{array}$ & & & & & & 1 & $-.026^{\star}$ & $.125^{\star \star}$ & -.013 & $.249^{\star \star}$ & $.103^{\star \star}$ & $-.052^{\star \star}$ \\
\hline & $\begin{array}{l}\text { Girl } \\
(\mathrm{N}= \\
6825)\end{array}$ & & & & & & 1 & $-.049^{\star \star}$ & $.16^{\star \star}$ & -.002 & $.20^{\star \star}$ & $.09^{\star \star}$ & $-.05^{\star \star}$ \\
\hline \multirow[t]{2}{*}{ ST } & $\begin{array}{l}\text { Boy } \\
(\mathrm{N}= \\
7009)\end{array}$ & & & & & & & 1 & $.26^{*}$ & $.26^{*}$ & $.088^{\star \star}$ & $.025^{*}$ & $-.032^{\star \star}$ \\
\hline & $\begin{array}{l}\text { Girl } \\
(\mathrm{N}= \\
6825)\end{array}$ & & & & & & & 1 & $.029^{\star}$ & $.047^{\star \star}$ & $.07^{\star \star}$ & $.032^{\star \star}$ & $-.059^{\star \star}$ \\
\hline \multirow[t]{2}{*}{$\begin{array}{l}\text { SLEEP } \\
\text { DU }\end{array}$} & $\begin{array}{l}\text { Boy } \\
(\mathrm{N}= \\
7009)\end{array}$ & & & & & & & & 1 & $-.028^{\star}$ & $.182^{\star \star}$ & $.066^{\star \star}$ & $-.192^{\star \star}$ \\
\hline & $\begin{array}{l}\text { Girl } \\
(\mathrm{N}= \\
6825)\end{array}$ & & & & & & & & 1 & $-.028^{\star}$ & $.176^{\star \star}$ & $.049^{\star \star}$ & $-.183^{\star \star}$ \\
\hline \multirow[t]{2}{*}{ ZBMI } & $\begin{array}{l}\text { Boy } \\
(N= \\
7009)\end{array}$ & & & & & & & & & 1 & .02 & -.02 & $.032^{\star \star}$ \\
\hline & $\begin{array}{l}\text { Girl } \\
(\mathrm{N}= \\
6825)\end{array}$ & & & & & & & & & 1 & -.014 & -.02 & $.063^{\star \star}$ \\
\hline SC & $\begin{array}{l}\text { Boy } \\
(N= \\
7009)\end{array}$ & & & & & & & & & & 1 & $.055^{\star \star}$ & $-.13^{\star \star}$ \\
\hline
\end{tabular}




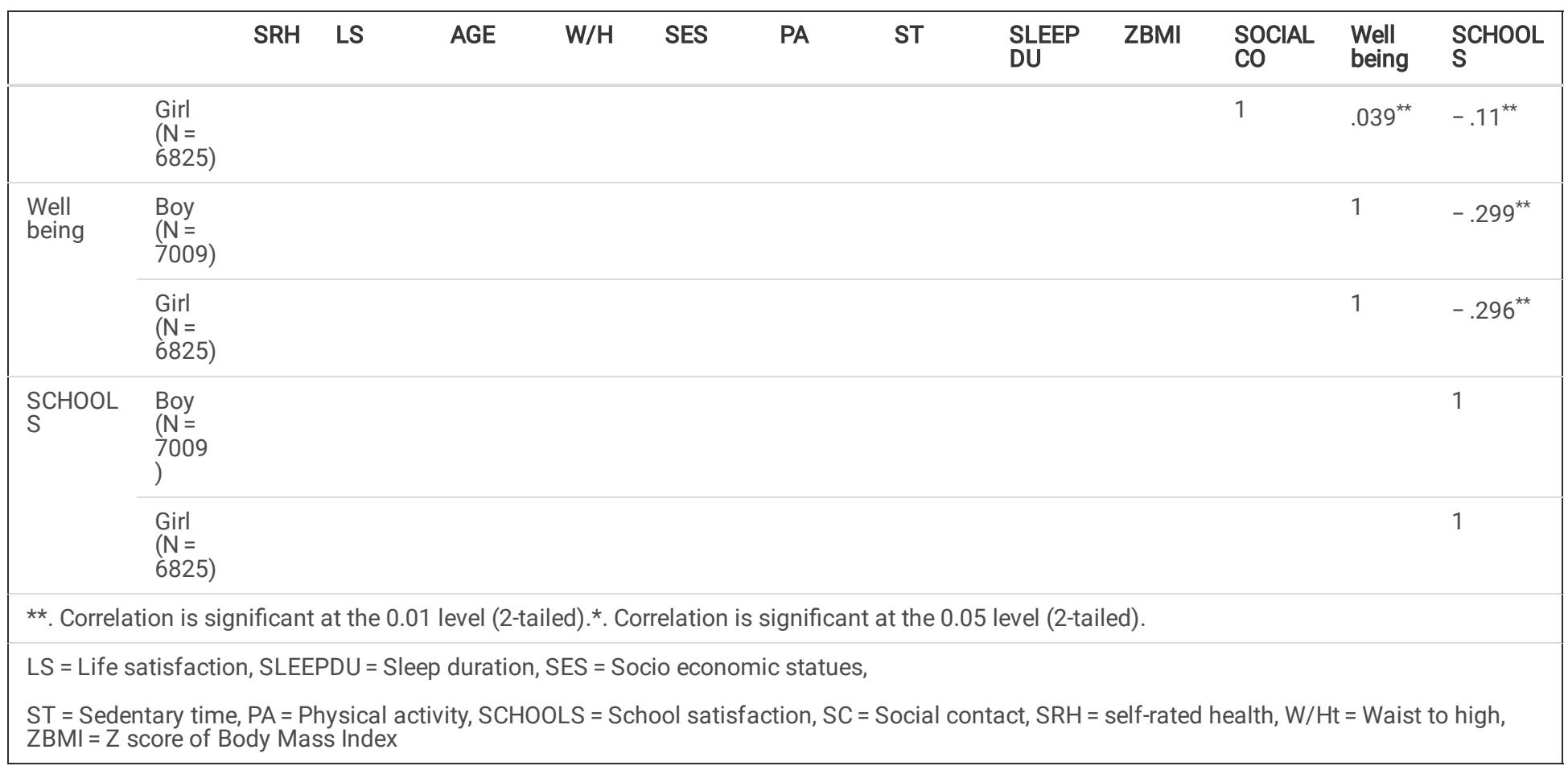


Table 2

Direct effects of variables in Iranian children and adolescents

\begin{tabular}{|c|c|c|c|c|c|c|}
\hline \multirow{3}{*}{$\mathrm{AGE} \rightarrow \mathrm{PA}$} & \multicolumn{3}{|l|}{ BOY } & \multicolumn{3}{|l|}{ GIRL } \\
\hline & estimate & $\begin{array}{l}\text { standardized } \\
\text { estimate }\end{array}$ & T-VALUE & estimate & $\begin{array}{l}\text { standardized } \\
\text { estimate }\end{array}$ & T-VALUE \\
\hline & -0.0112 & -0.036 & $3.39 *$ & -0.02 & -0.0456 & 1.03 \\
\hline $\mathrm{AGE} \rightarrow \mathrm{LS}$ & -0.026 & -0.037 & $3.337 *$ & -0.020 & -0.028 & $2.483 *$ \\
\hline $\mathrm{AGE} \rightarrow \mathrm{SCHOOLS}$ & 0.495 & 0.062 & $5.255 *$ & 0.089 & 0.112 & $9.381 *$ \\
\hline $\mathrm{AGE} \rightarrow \mathrm{W} / \mathrm{Ht}$ & -0.004 & -0.001 & 0.65 & -0.006 & -0.334 & $29.14 *$ \\
\hline $\mathrm{AGE} \rightarrow \mathrm{ZBMI}$ & 0.125 & 0.374 & $33.72 *$ & 0.146 & 0.491 & $46.62 *$ \\
\hline $\mathrm{SES} \rightarrow \mathrm{PA}$ & 0.0373 & 0.037 & $3.147 *$ & 0.123 & 0.324 & 1.34 \\
\hline $\mathrm{SES} \rightarrow \mathrm{ZBMI}$ & 0.0304 & 0.028 & $2.203 *$ & 0.0207 & 0.0121 & 0.765 \\
\hline $\mathrm{SES} \rightarrow \mathrm{SC}$ & -0.133 & -0.036 & $3.153 *$ & -0.003 & -0.002 & 1.67 \\
\hline $\mathrm{SES} \rightarrow \mathrm{ST}$ & 0.031 & 0.045 & $3.78 *$ & 0.0159 & 0.023 & 1.97 \\
\hline $\mathrm{SES} \rightarrow \mathrm{W} / \mathrm{Ht}$ & 0.002 & 0.033 & $3.08 *$ & 0.0101 & 0.022 & 1.43 \\
\hline $\mathrm{FS} \rightarrow$ WELLBEING & -0.07 & -0.023 & $1.99 *$ & -0.107 & -0.033 & $2.820 *$ \\
\hline $\mathrm{FS} \rightarrow \mathrm{ZBMI}$ & -0.052 & -0.065 & 1.09 & -0.032 & $-0 / 061$ & $4.797 *$ \\
\hline SLEEPDU $\rightarrow$ PA & 0.098 & 0.123 & $10.358 *$ & 0.126 & 0.162 & $13.55 *$ \\
\hline SLEEPDU $\rightarrow$ SRH & -0.028 & -0.045 & $4.122 *$ & -0.043 & -0.07 & $6.35 *$ \\
\hline $\mathrm{PA} \rightarrow \mathrm{SRH}$ & 0.036 & 0.046 & $4.09 *$ & -.0403 & 0.061 & $4.489 *$ \\
\hline $\mathrm{PA} \rightarrow$ WELLBEING & 0.007 & 0.088 & $4.245 *$ & 0.383 & 0.077 & $6.637 *$ \\
\hline $\mathrm{PA} \rightarrow \mathrm{SC}$ & 0.91 & 0.250 & $21.65 *$ & 0.717 & 0.206 & $17.44 *$ \\
\hline $\mathrm{PA} \rightarrow \mathrm{SCHOOLS}$ & -0.049 & -0.019 & 1.59 & 0.089 & 0.034 & $2.763 *$ \\
\hline $\mathrm{ST} \rightarrow \mathrm{LS}$ & 0.181 & 0.055 & $4.96 *$ & 0.166 & 0.048 & $4.26 *$ \\
\hline $\mathrm{ST} \rightarrow \mathrm{PA}$ & -0.036 & -0.026 & $2.179 *$ & -0.078 & -0.054 & $4.49 *$ \\
\hline $\mathrm{ST} \rightarrow \mathrm{SC}$ & 0.497 & 0.096 & 8.304* & 0.417 & 0.083 & $6.97 *$ \\
\hline $\mathrm{ST} \rightarrow \mathrm{SCHOOLS}$ & -0.087 & -0.024 & $2.024 *$ & -0.221 & -0.058 & $4.809 *$ \\
\hline $\mathrm{SC} \rightarrow \mathrm{SRH}$ & 0.0195 & 0.091 & $8.122 *$ & 0.023 & 0.101 & $9.09 *$ \\
\hline $\mathrm{SC} \rightarrow \mathrm{SCHOOLS}$ & 0.086 & 0.123 & $10.27 *$ & .00907 & 0.201 & 1.45 \\
\hline $\mathrm{SCHOOLS} \rightarrow \mathrm{LS}$ & 0.224 & 0.249 & $21.32 *$ & 0.223 & 0.250 & $20.89 *$ \\
\hline $\mathrm{SCHOOLS} \rightarrow \mathrm{SRH}$ & 0.0641 & 0.210 & $17.913 *$ & 0.0671 & 0.223 & $18.83 *$ \\
\hline SCHOOLS $\rightarrow$ WELL BEING & 0.171 & 0.203 & 1.34 & 0.547 & 0.29 & $25.02 *$ \\
\hline WELLBEING $\rightarrow$ LS & 0.0892 & 0.186 & $16.001 *$ & 0.082 & 0.176 & $14.74 *$ \\
\hline WELLBEING $\rightarrow$ SRH & 0.007 & 0.049 & $4.245 *$ & 0.006 & 0.41 & $3.55 *$ \\
\hline $\mathrm{LS} \rightarrow \mathrm{SRH}$ & 0.097 & 0.288 & $24.93 *$ & 0.096 & 0.287 & $24.81 *$ \\
\hline $\mathrm{ZBMI} \rightarrow \mathrm{W} / \mathrm{Ht}$ & 0.029 & 0.46 & $43.5 *$ & 0.043 & 0.648 & $56.49 *$ \\
\hline
\end{tabular}


Table 3

Total effect of variable on Life Satisfaction in Iranian children and adolescents

\begin{tabular}{|c|c|c|c|c|c|c|}
\hline & BOY & & & GIRL & & \\
\hline & Direct effect & Indirect effect & Total effect & Direct effect & Indirect effect & Total effect \\
\hline Age & $-0.037 *$ & $0.0146 *$ & $-0.022 *$ & $-0.028 *$ & $0.033 *$ & $-0.005 *$ \\
\hline ST & $0.055 *$ & $-0.0029 *$ & $0.052 *$ & $0.048 *$ & $-0.011 *$ & $0.037 *$ \\
\hline School satisfaction & $0.249 *$ & - & $0.249 *$ & $0.250 *$ & $0.049 *$ & $.299 *$ \\
\hline Well being & $0.186 *$ & - & $0.186 *$ & $0.176 *$ & - & $0.176 *$ \\
\hline Sleep duration & - & $0.0029 *$ & $0.0029 *$ & - & $0.005 *$ & $0.005 *$ \\
\hline PA & & $0.0236 *$ & $0.0236 *$ & - & $0.03 *$ & $0.03 *$ \\
\hline Family size & - & $-0.0004 *$ & $-0.0004 *$ & - & $-0.005 *$ & $-0.005 *$ \\
\hline SES & - & $0.002 *$ & $0.002 *$ & - & $0.001 *$ & $0.001 *$ \\
\hline Social contact & - & $0.03 *$ & $0.03 *$ & - & $0.636 *$ & $0.636 *$ \\
\hline
\end{tabular}

Table 4

Total effect of variable on self-rated health in Iranian children and adolescents

\begin{tabular}{|c|c|c|c|c|c|c|}
\hline & \multicolumn{3}{|l|}{ BOY } & \multicolumn{3}{|l|}{ GIRL } \\
\hline & Direct effect & Indirect effect & Total effect & Direct effect & Indirect effect & Total effect \\
\hline Age & - & $-0.0046 *$ & $-0.0046 *$ & - & $-0.017 *$ & $-.017 *$ \\
\hline ST & - & $-1.99 *$ & $-1.99 *$ & - & $-0.145 *$ & $-0.145 *$ \\
\hline School satisfaction & $0.210 *$ & $0.0717 *$ & $0.28 *$ & $0.223 *$ & $0.21 *$ & $0.433 *$ \\
\hline Well being & $0.049 *$ & $0.052 *$ & $.101 *$ & $0.41 *$ & $.048 *$ & $.458 *$ \\
\hline Sleep duration & $-0.045 *$ & $.003 *$ & $-0.042 *$ & $-0.07 *$ & $0.09 *$ & $.02 *$ \\
\hline PA & $0.046 *$ & $0.016 *$ & $0.062 *$ & $0.061 *$ & $.077 *$ & $.138 *$ \\
\hline Family size & - & $-0.005 *$ & $-0.005 *$ & - & $-0.0137 *$ & $-0.0137 *$ \\
\hline SES & - & $0.015 *$ & $0.015 *$ & - & $0.058 *$ & $0.058 *$ \\
\hline SC & $0.091 *$ & $0.0338 *$ & $0.124 *$ & $0.101 *$ & $0.053 *$ & $0.154 *$ \\
\hline LS & $0.288 *$ & - & $0.288 *$ & $0.287 *$ & - & $0.287 *$ \\
\hline \multicolumn{7}{|l|}{$*=$ SIGNIFICANT } \\
\hline \multicolumn{7}{|c|}{ ST $=$ Sedentary time, PA = Physical activity, SES = Socio economic statues } \\
\hline
\end{tabular}

In case of SRH, school satisfaction, well-being, sleep duration, and physical activity had both direct and indirect effect on SRH in both genders. SRH was directly affected by LS ( 0.288 in boys \& 0.287 in girls); and indirectly affected by age $(-0.046$ in boys \& -0.017 in girls), sedentary time ( -1.99 in boys $\&-0.145$ in girls), family size ( -0.005 in boys \& -0.014 in girls), and SES ( 0.015 in boys \& 0.058 in girls). In both genders, LS had the greatest direct effect on $\mathrm{SRH}$. After that, school satisfaction had the greatest direct effect on SRH in boys and well-being had the greatest direct effect on SRH in girls (Figs. $1 \& 2$ ).

The results of model fitness with accepted range for evaluating the validity of the model are characterized in Table 5 . There are a variety of fit indices to evaluate the model. All of them demonstrated that the model had acceptable fitting.

Table 5

The results of model fitness

\begin{tabular}{|llllllll|}
\hline MODEL & $\mathbf{X}^{2}$ & df & CFI & GFI & NFI & RMSEA & IFI \\
\hline Boy & 668.93 & 49 & 0.95 & 0.97 & 0.94 & 0.04 & 0.95 \\
\hline Girl & 408.29 & 45 & 0.964 & 0.97 & 0.960 & 0.03 & 0.964 \\
\hline
\end{tabular}

Page $8 / 13$ 


\section{Discussion}

This study was designed to evaluate the important determinants of LS and SRH in nationwide representative sample of Iranian children and adolescents examining the direct and indirect effects of different physical and psychosocial status of children on their LS and SRH.

In this investigation, LS and SRH showed a strong correlation with each other. LS is an assessment of overall well-being and SRH indicates the adolescents' perception of their health and applies as an index for their physiological conditions $(3,19)$. The relationship of LS and SRH was reported in previous researches (20-22). Studies showed that individuals with a healthy lifestyle have better SRH and higher LS (23). The evaluation of LS and SRH from a holistic approach is very complex and so many factors influence them. In this study, we tried to determine the most effective factors in LS and SRH in children and adolescents. Through the path analytic method we found that among studied variables, school satisfaction and well-being had the greatest positive direct effect on both LS and SRH. Moreover, our results showed that the association between SES and LS was attributable to indirect effects through physical activity, ZBMI, social contact and sedentary time in boys and through sedentary time in girls. It means that higher SES improves physical activity, BMI, social contact and sedentary time in subjects which in turn leads to more LS. On the other hand, family size showed slight indirect effect on LS through its negative effect on wellbeing and BMI.

In consistence with our findings, recent studies have shown that satisfaction at school has positive effect on students' satisfaction with life by decreasing both the school drop-out rate and disruptive behaviors $(24,25)$. School satisfaction was shown to reduce the students' illness, raising positive emotions, life satisfaction and academic success (26). On average, subjects who have higher social contact, take part in physical activities, spend more time with family and friends seem to have greater satisfaction with life (5). As expected, all factors which decrease psychosocial stress in adolescents including having good relationships with family and friends, positive school environment and higher SES can improve subjective wellbeing and LS (27-30). The literature indicated that LS was predicted by variables related to population health and there was a strong correlation between LS and health behaviors (31-33). It is suggested that the individuals with normal BMI reported more LS than obese person (34). The study conducted by Ford et al. regarding the association of BMI with health-related quality of life showed that after adjusting for confounders, thin and obese people, had lower SRH and LS than people with normal BMI (34). Furthermore, an inverse association was shown between LS with negative health-related behaviors such as physical inactivity (31). These results are in line with our findings and show that appropriate BMI and physical activity as two main health behaviors seem to have positive effect on LS. Therefore, it needs to notice the significance of these factors on life and health satisfaction of children and adolescents and design health-promoting programs to improve health outcomes of them.

\section{Conclusion}

This study provides new evidence about the determinants of SRH and LS as important indicators for students' health care in a large sample of Iranian children and adolescents. However, the cross-sectional design of this study had a limited ability for demonstrating a causal relationship and understanding the possible changes of subscales over time and their predictive validity. Moreover, self-report measure of some potentially important factors including personality variables, increases the risk of biases in this method. Future studies with longitudinal design and several data collections are suggested in order to verify the main determinants of life satisfaction in children and adolescents to improve health, both in adolescence and later in life.

\section{Abbreviations}

BMI

body mass index

LS

Life satisfaction

PA

Physical activity

SES

Socioeconomic status

$\mathrm{SRH}$

self-rated health

ST

Sedentary time

\section{Declarations}

\section{Ethics declarations and consent to participate}

The study protocol was approved by the Research and Ethics Council of Isfahan University of Medical Sciences (code: 194049). Written informed consent and verbal assent were obtained from all the parents and students, respectively. This study was conducted according to the guidelines laid 
down in the Declaration of Helsinki, and all procedures involving human subjects were approved by Ethics Committee of Isfahan University of Medical Sciences.

\section{Consent for publication}

Not applicable.

\section{Availability of data and materials}

The datasets used and/or analyzed during the current study are available from the corresponding author on reasonable request.

\section{Competing interests}

The authors declare that they have no competing interests.

\section{Funding}

This study was funded by Isfahan University of Medical Sciences.

\section{Authors' contributions}

The concept of this study was proposed by M.Q., R.K., This study was designed by R.H., M.Q., R.K., Data collection or processing was done by R.H., M.E.M., Z.M., P.A., H.-S.E., Analysis or interpretation was performed by H.-S.E., M.Q., P.A, Z.M. Literature search was done by H.-S.E., M.Q., P.A. This study was written by H.-S.E., P.A. All authors have read and approved the manuscript.

\section{Acknowledgements}

The authors are thankful of all participants and large team working on this project in different provinces. We appreciate Isfahan University of Medical Sciences and other relevant national regulatory organizations (Project number: 194049) for supporting this project. The funder had only supporting role in this project.

\section{References}

1. Sawyer SM, Afifi RA, Bearinger LH, Blakemore S-J, Dick B, Ezeh AC, et al. Adolescence: a foundation for future health. The Lancet. 2012;379(9826):1630-40.

2. Currie C. Social determinants of health and well-being among young people. HBSC international report from the $2009 / 2010$ survey. Policy for Children and Adolescents, No. 6. 3. Adamson P, Bradshaw J, Hoelscher P, Richardson D. Child poverty in perspective: An overview of child well-being in rich countries 2007 .

4. Kelishadi R, Djalalinia S, Qorbani M, Mansourian M, Motlagh ME, Ardalan G, et al. Self-Rated health and life satisfaction in Iranian children and adolescents at the national and provincial level: the CASPIAN-IV study. Iranian Red Crescent Medical Journal. 2016;18(12.(

5. Branch-Allen R, Jayachandran J, editors. Determinants of life satisfaction in Canada: A causal modeling approach. SHS Web of Conferences; 2016: EDP Sciences.

6. Eriksson I, Undén A-L, Elofsson S. Self-rated health. Comparisons between three different measures. Results from a population study. International journal of epidemiology. 2001;30(2):326-33.

7. Veenhoven R. Developments in satisfaction-research. Social Indicators Research. 1996;37(1):1-46.

8. Blanchflower DG, Oswald AJ .Well-being over time in Britain and the USA. Journal of public economics. 2004;88(7-8):1359-86.

9. Siahpush M, Spittal M, Singh GK. Happiness and life satisfaction prospectively predict self-rated health, physical health, and the presence of limiting, long-term health conditions. American Journal of Health Promotion. 2008;23(1):18-26.

10. Streiner DL. Finding our way: an introduction to path analysis. The Canadian Journal of Psychiatry. 2005;50(2):115-22.

11. Motlagh ME, Ziaodini H, Qorbani M, Taheri M, Aminaei T, Goodarzi A, et al. Methodology and early findings of the fifth survey of childhood and adolescence surveillance and prevention of adult noncommunicable disease: The CASPIAN-V study. International journal of preventive medicine. 2017;8:4.

12. Kelishadi R, Majdzadeh R, Motlagh M-E, Heshmat R, Aminaee T, Ardalan G, et al. Development and evaluation of a questionnaire for assessment of determinants of weight disorders among children and adolescents: the Caspian-IV study. International journal of preventive medicine. 
13. Ahadi Z, Qorbani M, Kelishadi R, Ardalan G, Taslimi M, Mahmoudarabi M, et al. Regional disparities in psychiatric distress, violent behavior, and life satisfaction in Iranian adolescents: the CASPIAN-III study. Journal of Developmental \& Behavioral Pediatrics. 2014;35(9):582-90.

14. Kelishadi R, Motlagh ME, Roomizadeh P, Abtahi S-H, Qorbani M, Taslimi M, et al. First report on path analysis for cardiometabolic components in a nationally representative sample of pediatric population in the Middle East and North Africa (MENA): the CASPIAN-III Study. Annals of Nutrition and Metabolism. 2013;62(3):257-65.

15. Kelishadi R, Ardalan G, Qorbani M, Ataie-Jafari A, Bahreynian M, Taslimi M, et al. Methodology and early findings of the fourth survey of childhood and adolescence surveillance and prevention of adult non-communicable disease in Iran: The CASPIAN-IV study. International journal of preventive medicine. 2013;4(12):1451.

16. Cohen J, Cohen P, West SG, Aiken LS. Applied multiple regression/correlation analysis for the behavioral sciences: Routledge; 2013.

17. Wolfle LM. Strategies of path analysis. American Educational Research Journal. 1980;17(2):183-209.

18. Kline RB. Principles and practice of structural equation modeling. Guilford publications. 2015.

19. Warnoff C, Lekander M, Hemmingsson T, Sorjonen K, Melin B, Andreasson A. Is poor self-rated health associated with low-grade inflammation in 43110 late adolescent men of the general population? A cross-sectional study. BMJ open. 2016;6(4):e009440.

20. Keyes CL. Happiness, flourishing, and life satisfaction. The Wiley Blackwell encyclopedia of health, illness, behavior, and society. 2014:747-

51.

21. Diener E, Emmons RA, Larsen RJ, Griffin S. The satisfaction with life scale. Journal of personality assessment. 1985;49(1):71-5.

22. Palgi Y, Shmotkin D. The predicament of time near the end of life: Time perspective trajectories of life satisfaction among the old-old. Aging \& Mental Health. 2010;14(5):577-86.

23. Marques A, Peralta M, Santos T, Martins J, de Matos MG. Self-rated health and health-related quality of life are related with adolescents' healthy lifestyle .Public health. 2019;170:89-94.

24. Lewis AD, Huebner ES, Malone PS, Valois RF. Life satisfaction and student engagement in adolescents. Journal of Youth and Adolescence. 2011;40(3):249-62.

25. Elmore GM, Huebner ES. Adolescents' satisfaction with school experiences: Relationships with demographics, attachment relationships, and school engagement behavior. Psychology in the Schools. 2010;47(6):525-37.

26. Takakura M, Wake N, Kobayashi M. The contextual effect of school satisfaction on health-risk behaviors in Japanese high school students. Journal of School Health. 2010;80(11):544-51.

27. Addae EA. The mediating role of social capital in the relationship between socioeconomic status and adolescent wellbeing: evidence from Ghana. BMC public health. 2020; 20(1).

28. Patel V, Flisher AJ, Hetrick S, McGorry P. Mental health of young people: a global public-health challenge. The Lancet. 2007;369(9569):1302-

13.

29. DuBois DL, Silverthorn N. Natural mentoring relationships and adolescent health: Evidence from a national study. American journal of public health. 2005;95(3):518-24.

30. Freeman J, King M, Kuntsche E, Pickett W. Protective roles of home and school environments for the health of young Canadians. Journal of Epidemiology \& Community Health. 2011;65(5): 438-44.

31. Strine TW, Chapman DP, Balluz LS, Moriarty DG, Mokdad AH. The associations between life satisfaction and health-related quality of life, chronic illness, and health behaviors among US community-dwelling adults. Journal of community health. 2008; 33(1): 40-50.

32. Grant N, Wardle J, Steptoe A. The relationship between life satisfaction and health behavior: a cross-cultural analysis of young adults. International journal of behavioral medicine. 2009;16(3):259-68.

33. Karyani AK, Matin BK, Gebru AA, Dizaj JY, Rezaei S. Life and health satisfaction and their association toward health-related quality of life, body mass index and chronic diseases in Iran. Journal of education and health promotion. 2019;8. 
34. Wee HL, Cheung YB, Loke WC, Tan CB, Chow MH, Li SC, et al. The association of body mass index with health-related quality of life: an exploratory study in a multiethnic Asian population. Value in Health. 2008;11:S105-S14.

Figures

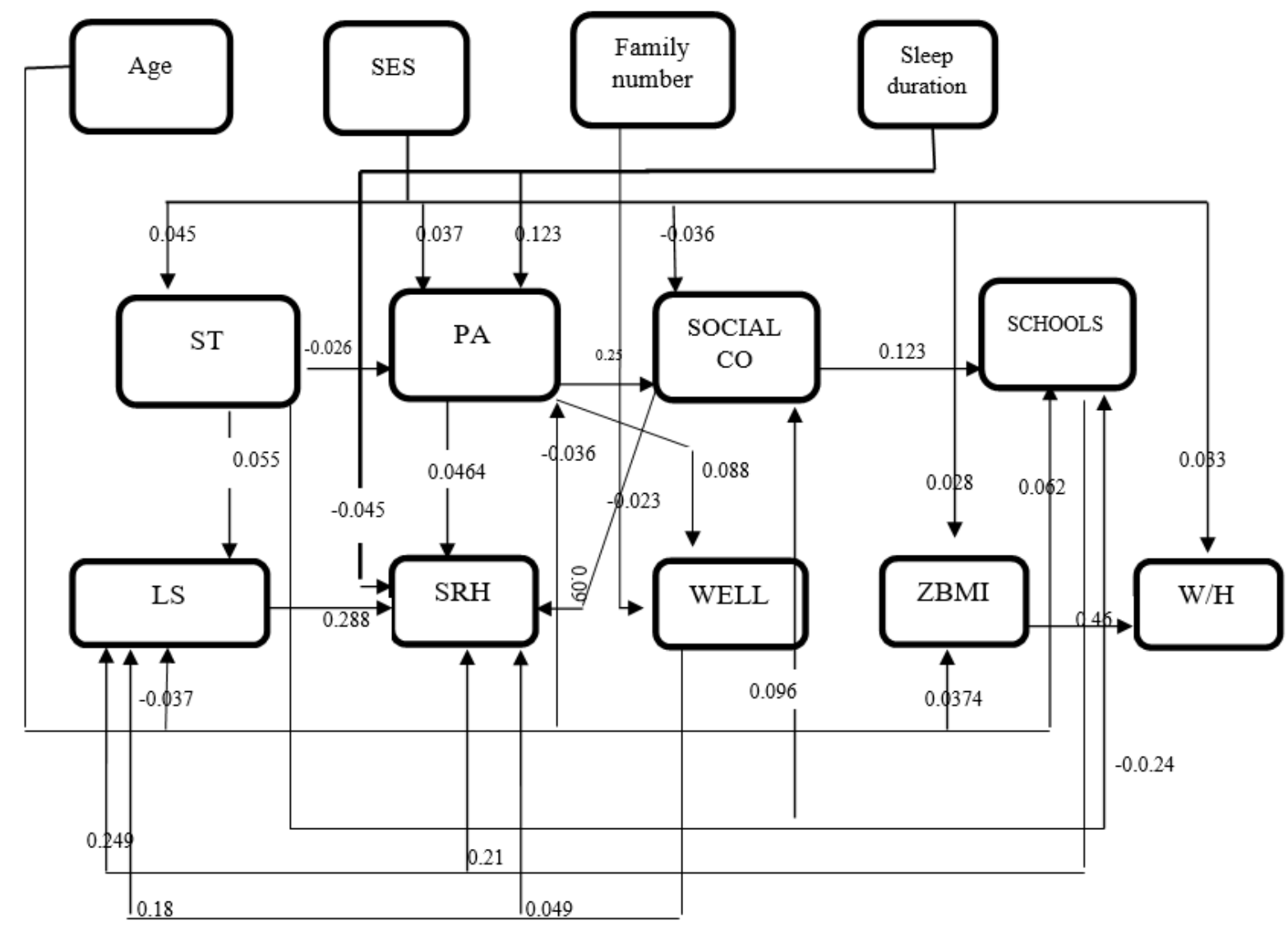

Figure 1

Path analysis diagram of association of general characteristics with life satisfaction and self-rated health for boys. 


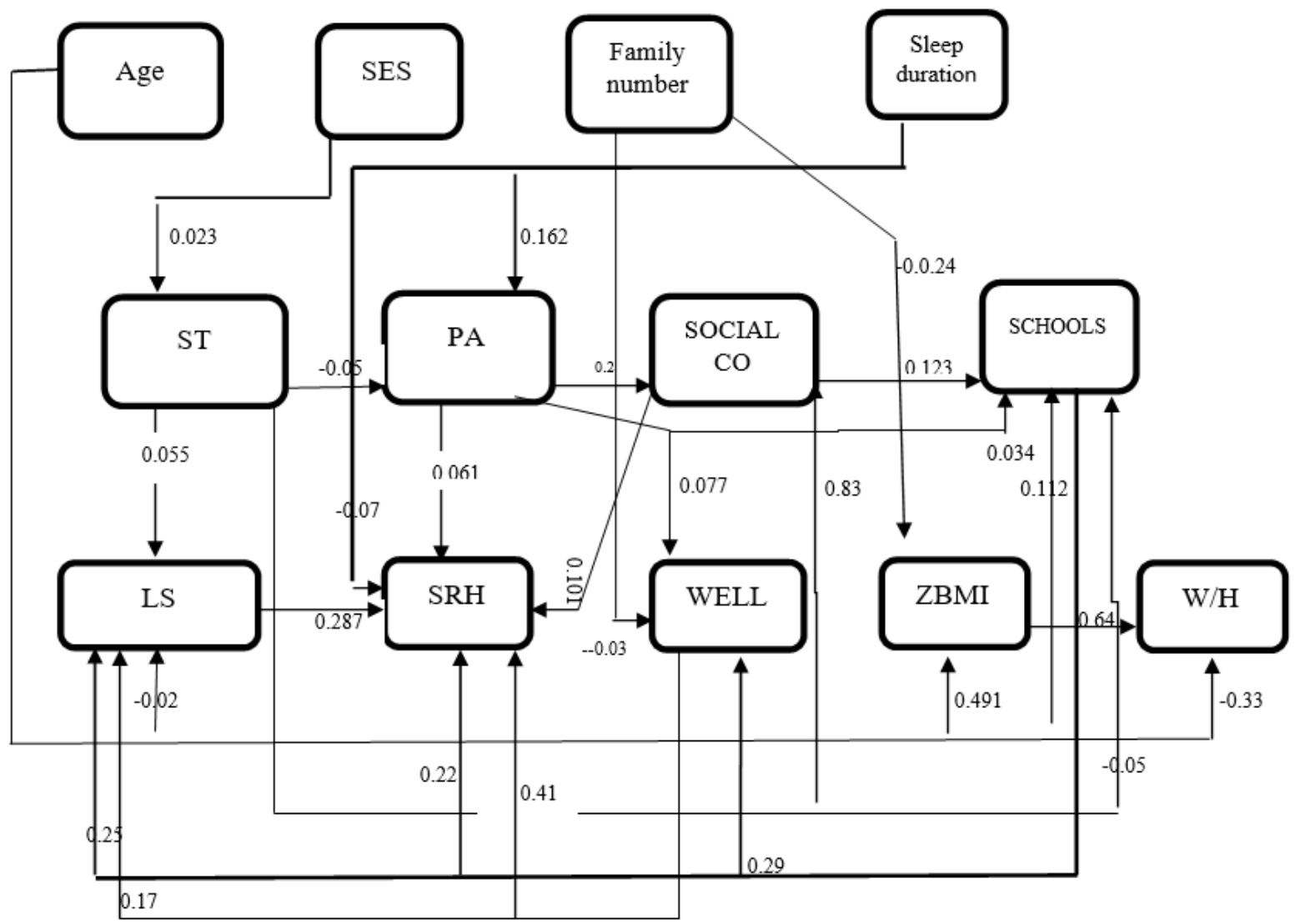

Figure 2

Path analysis diagram of association of general characteristics with life satisfaction and self-rated health for girls. 